\title{
Concurrent Relationship of Objectively Measured Physical Activity and Cardiorespiratory Fitness on Two Different Measures of Obesity in U.S. Adults
}

\author{
Peter D. Hart ${ }^{1,2, *}$ \\ ${ }^{1}$ Health Promotion Program, Montana State University - Northern, Havre, MT 59501 \\ ${ }^{2}$ Kinesmetrics Lab, Montana State University - Northern, Havre, MT 59501 \\ *Corresponding author: peter.hart@msun.edu
}

Received July 03, 2018; Revised September 02, 2018; Accepted September 12, 2018

\begin{abstract}
Background: Few population-based studies have examined the relationship of both physical activity (PA) and cardiorespiratory fitness (CRF) on the growing health problem of obesity. The purpose of this study was to examine the concurrent relationship of PA and CRF on two different measures of obesity. Methods: This study used data from adults 20-49 years of age participating in the 2003-2004 National Health and Nutrition Examination Survey (NHANES). Moderate-to-vigorous PA (MVPA, min/day) was objectively determined by use of accelerometer and participants were categorized into low or high groups using the median. CRF $(\mathrm{ml} / \mathrm{kg} / \mathrm{min})$ was assessed using a submaximal treadmill test and measures were categorized into low or high values by applying age- and sex-specific standards. Using body mass index (BMI), participants were categorized as obese if their values were $30 \mathrm{~kg} / \mathrm{m}^{2}$ or greater. Using waist circumference (WC), participants were categorized as obese if their values were greater than 88 (females) or $102 \mathrm{~cm}$ (males). Linear regression was used to test for mean CRF differences in study variables. Logistic regression was used to model the relationship between MVPA, CRF and obesity. Results: Participants in the high CRF group had significantly $(\mathrm{ps}<.05)$ greater MVPA across all obesity groupings. In BMI obese, neither BMI nor WC were significantly different between CRF groups. However, in WC obese, both BMI and WC were significantly (ps $<.05$ ) lower in the high CRF group. Among adults with low CRF, those with low MVPA were more than twice as likely to be obese than those with high MVPA using BMI ( $\mathrm{OR}=2.48 ; 95 \%$ CI: $1.23-5.01)$ and WC $(\mathrm{OR}=2.06$; $95 \%$ CI: 1.29-3.29). Among adults with high CRF, no MVPA and obesity relationship was seen. Conclusion: Results from this study indicate that PA is only related to obesity when CRF is low. Furthermore, high CRF may protect less physically active adults from both overall and abdominal obesity.
\end{abstract}

Keywords: physical activity, obesity, cardiorespiratory, epidemiology

Cite This Article: Peter D. Hart, "Concurrent Relationship of Objectively Measured Physical Activity and Cardiorespiratory Fitness on Two Different Measures of Obesity in U.S. Adults." Journal of Physical Activity Research, vol. 3, no. 2 (2018): 78-81. doi: 10.12691/jpar-3-2-3.

\section{Introduction}

Physical activity (PA) is a health behavior promoted to all individuals because of its preventive relationship with disease $[1,2,3,4,5]$, its positive relationship with longevity $[6,7,8,9,10]$, and its ability to enhance health-related quality of life (HRQOL) $[11,12,13,14]$. Cardiorespiratory fitness (CRF) is a trait possessed by individuals, characterized by the ability to engage in dynamic exercise of at least moderate intensity for prolonged periods [15], and is also related to positive health outcomes $[16,17,18,19,20]$. Obesity is a growing concern world-wide [21] with health promotion efforts directed toward increasing PA and modifying diet $[22,23,24]$. However, few efforts have been directed toward improving both PA along with CRF in the primary and tertiary prevention of obesity. Furthermore, data examining the obesity relationship with both PA and CRP are sparse. Therefore, the purpose of this study was to examine the concurrent relationship of PA and CRF on two different measures of obesity.

\section{Methods}

\subsection{Study Design}

Data for this research came from the 2003-04 National Health and Nutrition Examination Survey (NHANES) [25]. The sample consisted of participants who were 20-49 years of age and had complete PA, CRF, and body composition data.

\subsection{Variables Utilized}

The two main independent variables were moderate-tovigorous PA (MVPA) and CRF. The two main dependent variables were obesity status measured by body mass index 
(BMI) and obesity status measured by waist circumference (WC). Covariates were age, sex, race, and income.

\subsection{Assessment of MVPA and CRF}

MVPA (min/day) was objectively determined by use of accelerometer and participants were categorized into low or high groups using the median. CRF $(\mathrm{ml} / \mathrm{kg} / \mathrm{min})$ was assessed using a submaximal treadmill test and measures were categorized into low or high values by applying ageand sex-specific standards [26,27].

\subsection{Assessment of Obesity}

Using BMI, participants were categorized as obese if their values were $30 \mathrm{~kg} / \mathrm{m}^{2}$ or greater. Using WC, participants were categorized as obese if their values were greater than 88 (females) or $102 \mathrm{~cm}$ (males) [28].

\subsection{Statistical Analyses}

Participant characteristics were described using means, percentages, standard errors (SEs) and 95\% confidence intervals (CIs) (Table 1). Linear regression was used to test for mean CRF differences in study variables (Table 2). Multiple logistic regression was used to model the relationship between MVPA, CRF and obesity by computing adjusted odds ratios (ORs) and $95 \%$ CIs (Table $3 \&$ Table 4). SAS version 9.4 was used for all analyses $[29,30,31]$.

Table 1. Participant characteristics, U.S. adults 20 to 49 years of age (2003-2004)

\begin{tabular}{|c|c|c|c|c|c|}
\hline Characteristic & $\mathrm{N}$ & Mean $/ \%$ & $S E$ & \multicolumn{2}{|c|}{$95 \% C I$} \\
\hline Age (years) & 1386 & 36.0 & 0.29 & 35.44 & 36.65 \\
\hline Sex (Males)* & 1386 & 50.0 & 1.79 & 46.14 & 53.77 \\
\hline Race/ethnicity (White)* & 1386 & 71.0 & 3.20 & 64.16 & 77.82 \\
\hline Income $(<45 \mathrm{~K} \text { US } \$)^{*}$ & 1303 & 40.8 & 2.18 & 36.17 & 45.44 \\
\hline BMI $\left(\mathrm{kg} / \mathrm{m}^{2}\right)$ & 1385 & 27.9 & 0.21 & 27.46 & 28.36 \\
\hline MVPA (average min/day) & 1386 & 30.1 & 1.08 & 27.77 & 32.37 \\
\hline ST (average min/day) & 1386 & 458.9 & 4.72 & 448.86 & 468.96 \\
\hline $\mathrm{CRF}(\mathrm{ml} / \mathrm{kg} / \mathrm{min})$ & 684 & 39.1 & 0.51 & 37.99 & 40.17 \\
\hline
\end{tabular}

Note. *indicates percentages (\%) were reported. SE is standard error. BMI is body mass index $\left(\mathrm{kg} / \mathrm{m}^{2}\right)$. WC is waist circumference (cm). MVPA is objectively measured moderate-to-vigorous physical activity (average min/day). ST is sedentary time (average min/day). CRF is cardiorespiratory fitness as measured by $\mathrm{VO} 2_{\max }(\mathrm{ml} / \mathrm{kg} / \mathrm{min})$.

Table 2. Participant characteristics by CRF level and obese status, U.S. adults 20 to 49 years of age (2003-2004)

\begin{tabular}{|c|c|c|c|c|c|c|c|c|c|c|}
\hline \multirow[b]{3}{*}{ Characteristic } & \multicolumn{5}{|c|}{ Obese } & \multicolumn{5}{|c|}{ Not Obese } \\
\hline & \multicolumn{2}{|c|}{ Lower CRF } & \multicolumn{2}{|c|}{ Higher CRF } & \multirow[b]{2}{*}{$p$} & \multicolumn{2}{|c|}{ Lower CRF } & \multicolumn{2}{|c|}{ Higher CRF } & \multirow[b]{2}{*}{$p$} \\
\hline & Mean $/ \%$ & $S E$ & Mean $/ \%$ & $S E$ & & Mean $/ \%$ & $S E$ & Mean $/ \%$ & $S E$ & \\
\hline \multicolumn{11}{|l|}{ Using BMI } \\
\hline Age (years) & 35.3 & 0.88 & 36.7 & 0.70 & .398 & 33.9 & 0.76 & 34.2 & 0.58 & .774 \\
\hline Sex (Males)* & 62.9 & 6.35 & 59.0 & 3.54 & .576 & 53.3 & 2.91 & 47.1 & 3.95 & .162 \\
\hline Race/ethnicity (White)* & 70.4 & 6.62 & 68.3 & 4.49 & .808 & 67.8 & 4.96 & 79.5 & 2.95 & .014 \\
\hline Income $(<45 \mathrm{~K} \text { US } \$)^{*}$ & 39.4 & 7.24 & 33.2 & 6.17 & .388 & 34.7 & 3.08 & 37.1 & 2.68 & .551 \\
\hline $\operatorname{BMI}\left(\mathrm{kg} / \mathrm{m}^{2}\right)$ & 34.9 & 0.56 & 33.6 & 0.29 & .055 & 25.0 & 0.26 & 24.0 & 0.24 & .006 \\
\hline WC (cm) & 111.2 & 1.71 & 108.7 & 0.94 & .157 & 88.7 & 0.77 & 85.4 & 0.75 & .001 \\
\hline MVPA (average min/day) & 25.2 & 2.11 & 34.1 & 2.27 & .003 & 33.1 & 1.55 & 40.3 & 1.87 & .009 \\
\hline ST (average min/day) & 451.9 & 13.34 & 433.7 & 11.71 & .248 & 451.2 & 6.92 & 448.7 & 9.22 & .833 \\
\hline $\mathrm{CRF}(\mathrm{ml} / \mathrm{kg} / \mathrm{min})$ & 32.8 & 0.63 & 44.7 & 1.16 & $<.001$ & 33.8 & 0.43 & 45.2 & 0.73 & $<.001$ \\
\hline \multicolumn{11}{|l|}{ Using WC } \\
\hline Age (years) & 35.9 & 0.49 & 37.7 & 0.66 & .119 & 33.2 & 0.80 & 33.1 & 0.54 & .948 \\
\hline Sex (Males)* & 52.8 & 5.96 & 46.0 & 3.56 & .339 & 58.3 & 3.03 & 52.0 & 4.36 & .202 \\
\hline Race/ethnicity (White)* & 72.9 & 5.21 & 69.6 & 4.39 & .513 & 65.5 & 5.24 & 81.4 & 2.18 & .003 \\
\hline Income $(<45 \mathrm{~K} \text { US } \$)^{*}$ & 36.5 & 5.17 & 34.5 & 5.75 & .763 & 35.9 & 3.07 & 37.0 & 3.72 & .823 \\
\hline $\operatorname{BMI}\left(\mathrm{kg} / \mathrm{m}^{2}\right)$ & 32.8 & 0.70 & 31.2 & 0.48 & .011 & 24.6 & 0.23 & 23.4 & 0.24 & $<.001$ \\
\hline $\mathrm{WC}(\mathrm{cm})$ & 107.9 & 1.55 & 103.8 & 1.10 & .016 & 86.5 & 0.52 & 83.2 & 0.71 & .002 \\
\hline MVPA (average min/day) & 24.3 & 1.68 & 34.4 & 2.63 & .004 & 35.1 & 1.50 & 41.5 & 1.44 & .001 \\
\hline ST (average min/day) & 451.0 & 13.15 & 449.5 & 8.91 & .992 & 450.9 & 7.57 & 442.4 & 11.04 & .516 \\
\hline $\mathrm{CRF}(\mathrm{ml} / \mathrm{kg} / \mathrm{min})$ & 32.1 & 0.58 & 43.5 & 0.47 & $<.001$ & 34.6 & 0.42 & 46.1 & 0.79 & $<.001$ \\
\hline
\end{tabular}

Note. *indicates percentages $(\%)$ were reported. SE is standard error. BMI is body mass index $\left(\mathrm{kg} / \mathrm{m}^{2}\right)$. WC is waist circumference (cm). Obese status was defined as a BMI of 30 or greater and a WC $>102 \mathrm{~cm}$ for males or $>88 \mathrm{~cm}$ for females. MVPA is objectively measured moderate-to-vigorous physical activity (average min/day). ST is sedentary time (average min/day). CRF is cardiorespiratory fitness as measured by VO $2_{\text {max }}$ ( $\mathrm{ml} / \mathrm{kg} / \mathrm{min}$ ). Least squares regression was performed on continuous variables to determine CRF-related differences. Rao-Scott Chi-square tests were performed on categorical variables to determine CRF-related differences. p-values in bold indicate significant differences at the .05 level. 
Table 3. Odds of being obese (from BMI) when comparing those with low objectively measured MVPA to those with high objectively measured MVPA, U.S. adults 20 to 49 years of age (2003-2004)

\begin{tabular}{|c|c|c|c|c|c|c|c|c|c|c|c|c|}
\hline \multirow{3}{*}{$\begin{array}{l}\text { MVPA groups } \\
\text { Overall }\end{array}$} & \multicolumn{4}{|c|}{ Model I } & \multicolumn{4}{|c|}{ Model II } & \multicolumn{4}{|c|}{ Model III } \\
\hline & \multirow[t]{2}{*}{ OR } & \multicolumn{2}{|c|}{$95 \% \mathrm{CI}$} & \multirow[t]{2}{*}{$p$} & \multirow[t]{2}{*}{ OR } & \multicolumn{2}{|c|}{$95 \% \mathrm{CI}$} & \multirow[t]{2}{*}{$p$} & \multirow[t]{2}{*}{ OR } & \multicolumn{2}{|c|}{$95 \% \mathrm{CI}$} & \multirow[t]{2}{*}{$p$} \\
\hline & & & & & & & & & & & & \\
\hline Low & 1.72 & 1.14 & 2.58 & .013 & 1.67 & 1.12 & 2.51 & .020 & 2.10 & 1.25 & 3.54 & .009 \\
\hline High & 1.00 & - & - & & 1.00 & - & - & & 1.00 & - & - & \\
\hline \multicolumn{13}{|l|}{ Lower CRF } \\
\hline Low & 2.02 & 1.08 & 3.78 & .030 & 1.98 & 1.05 & 3.75 & .037 & 2.48 & 1.23 & 5.01 & .015 \\
\hline High & 1.00 & - & - & & 1.00 & - & - & & 1.00 & - & - & \\
\hline \multicolumn{13}{|l|}{ Higher CRF } \\
\hline Low & 1.18 & 0.62 & 2.25 & .583 & 1.12 & 0.57 & 2.20 & .716 & 1.34 & 0.56 & 3.19 & .488 \\
\hline High & 1.00 & - & - & & 1.00 & - & - & & 1.00 & - & - & \\
\hline
\end{tabular}

Note. Obese status in this table was defined as a BMI of 30 or greater. MVPA is objectively measured moderate-to-vigorous physical activity. Model I is unadjusted. Model II is age-adjusted only. Model III is fully adjusted for age, sex, race, and income. OR is odds ratio. CI is confidence interval. Low MVPA represents those with objectively measured MVPA below the median. High MVPA represents those with objectively measured MVPA above the median. Values in bold are significantly different from 1.00, with $95 \%$ confidence. CRF is cardiorespiratory fitness. Lower CRF represents those with measured VO2max rated at age-sex-specific low to moderate fitness. Higher CRF represents those with measured VO2max rated at age-sexspecific high fitness.

Table 4. Odds of being obese (from WC) when comparing those with low objectively measured MVPA to those with high objectively measured MVPA, U.S. adults 20 to 49 years of age (2003-2004)

\begin{tabular}{|c|c|c|c|c|c|c|c|c|c|c|c|c|}
\hline \multirow{3}{*}{$\frac{\text { MVPA groups }}{\text { Overall }}$} & \multicolumn{4}{|c|}{ Model I } & \multicolumn{4}{|c|}{ Model II } & \multicolumn{4}{|c|}{ Model III } \\
\hline & \multirow[t]{2}{*}{ OR } & \multicolumn{2}{|c|}{$95 \% \mathrm{CI}$} & \multirow{2}{*}{$p$} & \multirow[t]{2}{*}{ OR } & \multicolumn{2}{|c|}{$95 \% \mathrm{CI}$} & \multirow[t]{2}{*}{$p$} & \multirow[t]{2}{*}{ OR } & \multicolumn{2}{|c|}{$95 \% \mathrm{CI}$} & \multirow[t]{2}{*}{$p$} \\
\hline & & & & & & & & & & & & \\
\hline Low & 1.82 & 1.27 & 2.61 & .003 & 1.75 & 1.23 & 2.49 & .004 & 1.64 & 1.03 & 2.62 & .040 \\
\hline High & 1.00 & - & - & & 1.00 & - & - & & 1.00 & - & - & \\
\hline \multicolumn{13}{|l|}{ Lower CRF } \\
\hline Low & 2.25 & 1.49 & 3.41 & .001 & 2.18 & 1.39 & 3.41 & .002 & 2.06 & 1.29 & 3.29 & .005 \\
\hline High & 1.00 & - & - & & 1.00 & - & - & & 1.00 & - & - & \\
\hline \multicolumn{13}{|l|}{ Higher CRF } \\
\hline Low & 1.32 & 0.73 & 2.39 & .339 & 1.21 & 0.66 & 2.22 & .517 & 1.01 & 0.38 & 2.66 & .988 \\
\hline High & 1.00 & - & - & & 1.00 & - & - & & 1.00 & - & - & \\
\hline
\end{tabular}

Note. Obese status in this table was defined as a WC $>102 \mathrm{~cm}$ for males or $>88 \mathrm{~cm}$ for females. MVPA is objectively measured moderate-to-vigorous physical activity. Model I is unadjusted. Model II is age-adjusted only. Model III is fully adjusted for age, sex, race, and income. OR is odds ratio. CI is confidence interval. Low MVPA represents those with objectively measured MVPA below the median. High MVPA represents those with objectively measured MVPA above the median. Values in bold are significantly different from 1.00 , with $95 \%$ confidence. CRF is cardiorespiratory fitness. Lower CRF represents those with measured VO2max rated at age-sex-specific low to moderate fitness. Higher CRF represents those with measured VO2max rated at age-sex-specific high fitness.

\section{Results}

Participants in the high CRF group had significantly $(\mathrm{ps}<.05)$ greater MVPA across all obesity groupings. In BMI obese, neither BMI nor WC were significantly different between CRF groups. However, in WC obese, both BMI and $\mathrm{WC}$ were significantly $(\mathrm{ps}<.05)$ lower in the high CRF group. Among adults with low CRF, those with low MVPA were more than twice as likely to be obese than those with high MVPA using BMI (OR=2.48; 95\% CI: 1.23-5.01) and WC (OR=2.06; 95\% CI: 1.29-3.29). Among adults with high CRF, no MVPA and obesity relationship was seen.

\section{Discussion}

The purpose of this study was to examine the relationship between concurrent PA and CRF on two different measures of obesity in middle-aged adults. Results showed, as expected, that adults with higher CRF also had greater amounts of MVPA. Additionally, this same trend was seen in both obese and non-obese adults using both BMI and WC. However, a not expected finding, was that non-BMI-obese adults with higher CRF had significantly smaller mean BMI and significantly smaller mean WC than their lower CRF counterparts. This same trend was also seen in the non-WC-obese adults. These finding suggest that CRF may be related to body weight among adults who are not classified as obese. Although not analyzed in this study, it is possible that CRF may differentiate between normal (BMI: <25) and overweight (BMI: 25 to 29.99) adults.

Another interesting finding in this study was that among adults with lower CRF, those with low MVPA were approximately twice as likely to be obese (by both BMI and WC), as compared to their high MVPA counterparts. Whereas, among adults with higher CRF, no MVPA and obesity relationship was seen. These finding suggest that CRF may protect adults from both types of obesity, regardless of MVPA behavior. Finally, these findings should be considered in light of the limitations associated with NHANES data [32]. 


\section{Conclusions}

Results from this study indicate that PA is only related to obesity when CRF is low. Furthermore, high CRF may protect less physically active adults from both overall and abdominal obesity. Health promotion programs should advocate for the improvement of CRF as well as increased PA in combating obesity.

\section{Acknowledgements}

No financial assistance was used to assist with this project.

\section{References}

[1] US Department of Health and Human Services, Office of Disease Prevention and Health Promotion. Healthy people 2020.

[2] Hart, P. D. (2018). Metabolic syndrome, health-related quality of life, and social risk: A structural equation modeling analysis. Journal of Physical Fitness, Medicine \& Treatment in Sports. 1(4): 555568 .

[3] Hart, P. D. (2018). Using structural equation modeling to examine the effects of sex and physical activity on the metabolic syndrome and health-related quality of life relationship. Exercise Medicine. $2: 3$.

[4] Hart, P. D., Benavidez, G. A., \& Erickson, J. (2017). Meeting recommended levels of physical activity in relation to preventive health behavior and health status among adults. Journal of Preventive Medicine and Public Health. 2017; 50(1):10-17.

[5] Hart, P. D. (2017). Contribution of physical activity to the Life's Simple 7 metric in older rural adults. American Journal of Cardiovascular Disease Research. 5(1): 1-4.

[6] Hart, P. D. (2017). Latent class analysis of physical activity and mortality in U.S. adults. Juniper Online Journal of Public Health. 3(1): 555602.

[7] Hart, P. D. (2017). A propensity score matched case-control study of historical physical activity and mortality in U.S. adults. Juniper Online Journal of Public Health. 2(5): 555600.

[8] Hart, P. D. (2017). Self-reported physical inactivity and waist circumference independently predict all-cause mortality in U.S. adults. American Journal of Public Health Research. 5(6): 184-189.

[9] Hart, P. D. (2017). Physical inactivity and health-related quality of life as predictors of survival in U.S. adults: A novel use of itemresponse theory. SM Preventive Medicine and Public Health. 1(2): 1010.

[10] Hart, P. D. (2017). Physical activity mode and survival in U.S adults. American Journal of Applied Mathematics and Statistics. 5(4): 154-158.

[11] Benavidez, G. A., \& Hart, P. D. (2017). Effects of yoga on measures of health-related quality of life from SF-36 and SF-12 assessments: A systematic review and meta-analysis. Exercise Medicine. 1:5.

[12] Hart, P. D. (2017). Physical activity and health-related quality of life in rural adults with chronic disease. American Journal of Medical Sciences and Medicine. 5(3): 62-66.

[13] Hart, P. D. (2016). Sex differences in the physical inactivity and health-related quality of life relationship among rural adults. Health Promotion Perspective. 2016; 6(4): 174-179.

[14] Hart, P. D. (2016). Meeting recommended levels of physical activity and health-related quality of life in rural adults. Journal of Lifestyle Medicine, 6(1): 1-6.
[15] American College of Sports Medicine (Ed.). (2013). ACSM's health-related physical fitness assessment manual. Lippincott Williams \& Wilkins.

[16] Clausen, J. S., Marott, J. L., Holtermann, A., Gyntelberg, F., \& Jensen, M. T. (2018). Midlife Cardiorespiratory Fitness and the Long-Term Risk of Mortality: 46 Years of Follow-Up. Journal of the American College of Cardiology, 72(9), 987-995.

[17] de Lannoy, L., Sui, X., Lavie, C. J., Blair, S. N., \& Ross, R. (2018, February). Change in Submaximal Cardiorespiratory Fitness and All-Cause Mortality. In Mayo Clinic Proceedings (Vol. 93, No. 2, pp. 184-190). Elsevier.

[18] Sloan, R. A., Sawada, S. S., Martin, C. K., Church, T., \& Blair, S. N. (2009). Associations between cardiorespiratory fitness and health-related quality of life. Health and quality of life outcomes, $7(1), 1$.

[19] Holtermann, A., Gyntelberg, F., Bauman, A., \& Jensen, M. T. (2017). Cardiorespiratory fitness, fatness and incident diabetes. diabetes research and clinical practice, 134, 113-120.

[20] Vainshelboim, B., Müller, J., Lima, R. M., Nead, K. T., Chester, C., Chan, K., ... \& Myers, J. (2017). Cardiorespiratory fitness and cancer incidence in men. Annals of epidemiology, 27(7), 442-447.

[21] Abarca-Gómez, L., Abdeen, Z. A., Hamid, Z. A., Abu-Rmeileh, N. M., Acosta-Cazares, B., Acuin, C., ... \& Agyemang, C. (2017). Worldwide trends in body-mass index, underweight, overweight, and obesity from 1975 to 2016: a pooled analysis of 2416 population-based measurement studies in 128.9 million children, adolescents, and adults. The Lancet, 390(10113), 2627-2642.

[22] Stankevitz, K., Dement, J., Schoenfisch, A., Joyner, J., Clancy, S. M., Stroo, M., \& Østbye, T. (2017). Perceived Barriers to Healthy Eating and Physical Activity Among Participants in a Workplace Obesity Intervention. Journal of occupational and environmental medicine, 59(8), 746-751.

[23] Meng, Y., Manore, M., Schuna, J., Patton-Lopez, M., Branscum, A., \& Wong, S. (2018). Promoting Healthy Diet, Physical Activity, and Life-Skills in High School Athletes: Results from the WAVE Ripples for Change Childhood Obesity Prevention Two-Year Intervention. Nutrients, 10(7), 947.

[24] Koo, H. C., Poh, B. K., \& Ruzita, A. T. (2016). Intervention on whole grain with healthy balanced diet to manage childhood obesity (GReat-Child ${ }^{\mathrm{TM}}$ trial): study protocol for a quasiexperimental trial. SpringerPlus, 5(1), 840.

[25] Centers for Disease Control and Prevention. National Center for Health Statistics. National Health and Nutrition Examination Survey: Plan and Operations, 1999-2010: https://wwwn.cdc.gov/nchs/nhanes/analyticguidelines.aspx.

[26] Centers for Disease Control and Prevention National Center for Health Statistics. NHANES 2003-2004 Laboratory Procedures Manual; 2004.

[27] Centers for Disease Control and Prevention National Center for Health Statistics. NHANES 2003-2004 Cardiovascular Fitness Procedures Manual; 2004.

[28] American College of Sports Medicine. ACSM's guidelines for exercise testing and prescription. Lippincott Williams \& Wilkins, 2013.

[29] Stokes ME, Davis CS, Koch GG. Categorical data analysis using SAS. Cary: SAS institute; 2012, p. 189-258.

[30] SAS Institute. Base SAS 9.4 procedures guide: statistical procedures; 2014 [cited 2016 Dec 27]. Available from: https://support.sas.com/documentation/cdl/en/procstat/67528/PDF/ default/procstat.pdf /

[31] Cody, R. P., \& Smith, J. K. (2006). Applied Statistics \& SAS Programming. Prentice Hall.

[32] Hart, P. D., \& Kang, M. (2014). Physical inactivity and healthrelated quality of life among U.S. adult men and women. Journal of Women's Health Care.3:6. 